\title{
Huntingtin Mediates Anxiety/Depression-Related Behaviors and Hippocampal Neurogenesis
}

\author{
Karim Ben M'Barek, ${ }^{1,2,3}$ Patrick Pla, ${ }^{1,2,3,5 \star}$ Sophie Orvoen, ${ }^{4 \star}$ Caroline Benstaali, ${ }^{1,2,3}$ Juliette D. Godin, ${ }^{1,2,3}$ \\ Alain M. Gardier, ${ }^{4}$ Frédéric Saudou, ${ }^{1,2,3}$ Denis J. David, ${ }^{4}$ and Sandrine Humbert ${ }^{1,2,3}$ \\ ${ }^{1}$ Institut Curie, ${ }^{2}$ CNRS UMR 3306, ${ }^{3}$ INSERM U1005, Orsay 91405, France, ${ }^{4}$ Universite Paris-Sud, EA3544, Faculté de Pharmacie, Châtenay-Malabry 92296, \\ France, and ${ }^{5}$ Universite Paris-Sud, Orsay 91405, France
}

Huntington disease (HD) is associated with early psychiatric symptoms including anxiety and depression. Here, we demonstrate that wild-type huntingtin, the protein mutated in HD, modulates anxiety/depression-related behaviors according to its phosphorylation at serines 1181 and 1201. Genetic phospho-ablation at serines 1181 and 1201 in mouse reduces basal levels of anxiety/depression-like behaviors. We observe that the reduction in anxiety/depression-like phenotypes is associated with increased adult hippocampal neurogenesis. By improving the attachment of molecular motors to microtubules, huntingtin dephosphorylation increases axonal transport of BDNF, a crucial factor for hippocampal adult neurogenesis. Consequently, the huntingtin-mediated increased BDNF dynamics lead to an increased delivery and signaling of hippocampal BDNF. These results support the notion that huntingtin participates in anxiety and depression-like behavior and is thus relevant to the etiology of mood disorders and anxiety/depression in HD.

\section{Introduction}

Huntington disease (HD) is a neurodegenerative disorder involving severe cognitive deterioration and motor impairment. Anxiety and depression are prevalent components of HD (Kirkwood et al., 2001; Duff et al., 2007): they are present early in the disease, before the diagnosis and preceding chorea by 10 years or more. Their etiology in HD is not known.

The mutation that causes HD is an abnormal polyglutamine (polyQ) expansion in the huntingtin (HTT) protein. HD is due to both the loss of the normal function(s) of wild-type HTT and the gain of toxic functions of polyQ-HTT (Zuccato et al., 2010). Wild-type HTT is an essential protein required for embryonic development (Duyao et al., 1995; Nasir et al., 1995; Zeitlin et al., 1995; White et al., 1997). It is important for the formation of the nervous system and embryonic neurogenesis in mouse (White et

Received Nov. 1, 2012; revised March 12, 2013; accepted March 26, 2013.

Author contributions: K.B., A.M.G., F.S., D.J.D., and S.H. designed research; K.B., P.P., S.O., C.B., J.D.G., and D.J.D. performed research; J.D.G., F.S., and S.H. contributed unpublished reagents/analytic tools; K.B., P.P., S.O., D.J.D., and S.H. analyzed data; K.B. and S.H. wrote the paper.

This work was supported by grants from Agence Nationale pour la Recherche, Maladies Rares (Grant ANR-09BLAN-0080), Association pour la Recherche sur le Cancer (ARC subvention libre ${ }^{\circ}$ 3188), Fédération pour la Recherche sur le Cerveau (FRC), CNRS, INSERM, and Institut Curie to S.H.. Fellowship support was provided by Fondation pour la Recherche Médicale (K.B.) and by the French Minister of Research (K.B., S.O.). The mouse mutant line was established at the Mouse Clinical Institute (Strasbourg, France) in the Targeted Mutagenesis and Transgenesis Department with funds from Grant ANR-09-BLAN-0080. P.P. and D.J.D. are assistant professors at Université ParisSud 11; A.M.G is professor at Université Paris-Sud 11; F.S. and S.H. are INSERM investigators. We thank the staff from Institut Curie facilities: Animal, Histology, Imaging, and Recombinant Protein and Antibody Platforms for help; $S$. Anne, R. Hen, and members of the Saudou and Humbert's laboratories for discussions.

The authors declare no competing financial interests.

*P.P. and S.0. contributed equally to this work.

Correspondence should be addressed to Dr. Sandrine Humbert, Institut Curie, CNRS UMR 3306, INSERM U1005, Centre Universitaire- Bat.110, Orsay 91405, France. E-mail: sandrine.humbert@curie.fr.

DOI:10.1523/JNEUROSCI.5110-12.2013

Copyright $\odot 2013$ the authors $\quad 0270-6474 / 13 / 338608-13 \$ 15.00 / 0$ al., 1997; Reiner et al., 2001; Godin et al., 2010). However, nothing is known about the role of HTT during adult neurogenesis.

The neurogenesis hypothesis of depression postulates that a decrease in the production of newborn granule cells in the dentate gyrus is related to the pathophysiology of major depressive disorders, whereas enhanced hippocampal neurogenesis is required for beneficial antidepressant treatment (Samuels and Hen, 2011; Petrik et al., 2012). In agreement, mice administered corticosterone show decreased neurogenesis associated with behavioral abnormalities mimicking depressive symptoms observed in humans (David et al., 2009). Conversely, chronic treatment with antidepressants increases neurogenesis in the dentate gyrus of the hippocampus in rodents and human (Malberg et al., 2000; Santarelli et al., 2003; Perera et al., 2011; Rainer et al., 2011; Boldrini et al., 2012). Studies have described a causative role for adult neurogenesis in the response to antidepressants in stress mouse models (David et al., 2009).

The brain-derived neurotrophic factor BDNF is at the crossroads of depression and neurogenesis. Although its expression is reduced by stress and in major depression disorder, it is induced by antidepressant treatment (Autry and Monteggia, 2012). Part of the effects of BDNF in the regulation of mood disorders has been linked to hippocampal neurogenesis. BDNF regulates dendritic maturation and survival of newly generated neurons in the dentate gyrus of the hippocampus (Krishnan and Nestler, 2008). BDNF is also a key factor in HD. BDNF is required by striatal neurons, the most affected neurons in HD, to survive and differentiate. However, the striatal production of BDNF is not sufficient (Baquet et al., 2004), and BDNF is provided to these neurons by cortical neurons through axonal transport. This microtubule (MT)-based transport depends on HTT and is altered in HD (Gauthier et al., 2004). 
We previously identified two cyclin-dependent kinase 5 (Cdk5) phosphorylation sites on HTT: serines 1181 and 1201 (S1181/1201) (Anne et al., 2007). Although phosphorylation at these sites is important to regulate oxidative stress- and polyQ-HTT-mediated toxicity in neuronal cultures, their function in physiological conditions is unknown (Anne et al., 2007). We report here that absence of phosphorylation of HTT at S1181/ 1201 reduces anxiety/depression-like behaviors and increases hippocampal neurogenesis in mouse.

\section{Materials and Methods}

Generation of mutant mouse lines. Hdh $h^{\text {S1181A/S1201A }}$ and $H d h^{\text {S1181D/S1201D }}$ mutant mouse lines were established at the MCI/ICS (Mouse Clinical Institute, Illkirch, France; http://www-mci.u-strasbg.fr). The targeting vectors were constructed as follows. A $0.7 \mathrm{~kb}$ fragment encompassing the two mutations in exon 27 was amplified by PCR using 129S2/SvPas DNA as a template and subcloned in an MCI proprietary vector resulting in step 1 vectors. These MCI vectors had a floxed neomycin resistance cassette. The two $3^{\prime}$ and $5^{\prime}$ homology arms were subsequently subcloned in step1 plasmid to generate the final targeting construct. The linearized constructs were electroporated in 129S2/SvPas mouse embryonic stem (ES) cells. After selection, targeted clones were identified by PCR using external primers and further confirmed by Southern blot with $5^{\prime}$ and $3^{\prime}$ external probes. Positive ES clones were injected into C57BL/6J blastocysts, and male chimeras derived gave germline transmission.

All experiments were performed with homozygous $H d h^{S 1181 A / S 1201 A}$ and $H d h^{S 1181 D / S 1201 D}$ mice derived from heterozygous crosses. The wildtype animals are originating from the two types of littermates (50/50). Littermates were kept in a $12 \mathrm{~h} \mathrm{light/dark}$ cycle in plastic cages, and allowed to eat and drink ad libitum. Bromodeoxyuridine [(BrdU) 150 $\mathrm{mg} / \mathrm{kg}$ ] was injected twice daily (morning and afternoon) during $3 \mathrm{~d}$ by intraperitoneal injections. Mice were sacrificed 3.5 weeks following the last injection.

All experiments were performed in strict accordance with the recommendations of the European Community (86/609/EEC) and the French National Committee $(87 / 848)$ for care and use of laboratory animals (permissions 91-448 to S.H. and 92-256B to D.J.D).

Genotyping. DNA was prepared from tails biopsies from mutant mice. Mutated regions containing LoxP sequence were genotyped using $5^{\prime}$-GC ACCCAGAGAACTCCTCCC-3' and 5'-CCTTCTCTTAGAGGGGACAT GGC-3' primers for $H d h^{S 1181 A / S 1201 A}$ mice, and 5'-CTTGTTCTCCAGGT

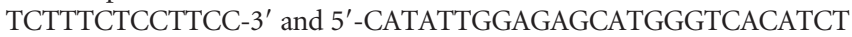
GG-3' primers for $H d h^{S 1181 D / S 1201 D}$ mice in Thermopol buffer (Biolabs), $200 \mu \mathrm{M}$ dNTPs, $1 \mu \mathrm{M}$ primers, and 5U/ $\mu \mathrm{l}$ TaqDNA polymerase (Biolabs). Cycling conditions were $3 \mathrm{~min}$ at $94^{\circ} \mathrm{C}, 2 \times\left(1 \mathrm{~min}\right.$ at $94^{\circ} \mathrm{C} ; 1 \mathrm{~min}$ at $62^{\circ} \mathrm{C} ; 1$ min at $\left.72^{\circ} \mathrm{C}\right), 30 \times\left(30 \mathrm{~s}\right.$ at $94^{\circ} \mathrm{C} ; 30 \mathrm{~s}$ at $62^{\circ} \mathrm{C} ; 30 \mathrm{~s}$ at $\left.72^{\circ} \mathrm{C}\right), 3 \mathrm{~min}$ at $72^{\circ} \mathrm{C}$. PCR products were separated on a $2 \%$ agarose gel to distinguish wild-type from mutant band.

Sequencing. Sequencing was carried on by MWG operon (France) from PCR products purified using Nucleospin Extract II (MachereyNagel). The sequences obtained were aligned to huntingtin gene sequence from PubMed with the Serial cloner 2.0 software (available at: http://serialbasics.free.fr/Serial_Cloner.html).

Behavioral testing. Behavioral testing was performed as described previously (David et al., 2009).

Immunohistochemistry. Mice were anesthetized with ketamine $(250 \mathrm{mg} /$ $\mathrm{ml} ; 100 \mu \mathrm{l} / 10 \mathrm{~g}$ of body weight) by intraperitoneal injections. Mice were then perfused with a saline solution and, after complete blood clearing, by paraformaldehyde (PFA) 4\%. Brains were removed and kept in PFA 4\% overnight. They were then cryoprotected in $30 \%$ sucrose. Frozen blocks were sectioned at $35 \mu \mathrm{m}$ and slices were kept free-floating in PBS with $0.1 \%$ azide. Serial sections were made, each one covering the whole hippocampus.

TUNEL staining was performed with DeadEnd Fluorometric TUNEL System (Promega) according to the manufacturer's instruction, with the addition of a prior permeabilization step in $0.5 \%$ Triton X-100 in PBS during $1 \mathrm{~h}$ at room temperature.

For BrdU immunostaining, slices were first treated using $0.01 \mathrm{M}$ citric acid. Peroxydase was quenched by $0.3 \% \mathrm{H}_{2} \mathrm{O}_{2}$ in $0.1 \mathrm{M}$ TBS. Slices were then permeabilized with $0.1 \%$ trypsin in $0.1 \mathrm{~m}$ Tris $\mathrm{HCl}$ with $0.1 \% \mathrm{CaCl}$, and transferred in $2 \mathrm{~N} \mathrm{HCl}$ solution. Slices were blocked with $10 \%$ normal donkey serum in PBS 0.5\% Tween 20. They were incubated with rat anti-BrdU Antibody (AbD Serotec) in blocking solution overnight. Secondary biotinylated donkey anti-rat was used and revelation was performed using Vector ABC Elit kit and Vectastain DAB kit. Sections were counterstained with hematoxylin, dehydrated in ethanol, delipidated in xylene, and mounted with Entellan.

For doublecortin (DCX) immunostaining, slices were washed with $0.1 \mathrm{M}$ TBS. Peroxydase were quenched by $0.3 \% \mathrm{H}_{2} \mathrm{O}_{2}$ in $0.1 \mathrm{M}$ TBS. Slices were blocked with $10 \%$ normal donkey serum in $0.1 \mathrm{M}$ TBS with $0.5 \%$ Triton X100. Slices were then incubated overnight at $4^{\circ} \mathrm{C}$ in blocking solution containing goat anti-DCX antibody (Santa Cruz Biotechnology). After washing, slices were incubated with biotinylated donkey antigoat. Revelation was performed as described for BrdU immunostaining and sections were dehydrated and mounted as before.

For Sholl analysis, DCX-positive cells with tertiary, relatively untruncated dendritic branches were traced for each $35 \mu \mathrm{m}$ hippocampal slice using Neurolucida software (MicroBrightField) on an Olympus BX51 microscope equipped with a motorized stage device and $\times 100$ immersion oil objective. DCX immunohistochemistry was done to maximize the labeling of dendrites. Sholl analysis for dendritic complexity was performed using the accompanying software (NeuroExplorer; MicroBrightField, version 10), calculating dendritic complexity including dendritic length and number of intersections (branch points). All samples were number coded, and analysis was done blind to treatment.

RNA extraction, microarray, and real-time PCR. Total RNA was isolated from frozen hippocampi using miRNeasy mini kit (Qiagen). Total RNAs were monitored using the Nanodrop (Thermo) and the Agilent Bioanalyzer. Total RNA RIN values were between 8.3 and 9.1. RNA samples were retrotranscribed using the First-Strand cDNA Synthesis Kit (Invitrogen). cDNAs were diluted 1:10 and submitted to RT-PCR with 7900HT Fast real time PCR system (Applied Biosystems) using power SYBR Green PCR Master mix (Applied Biosystems). Oligonucleotide pairs were for BDNF IV (5'-AGCTGCCTTGATGTTTACTTT-3' and 5'-TCCGTGGACGTTTACTTCTT-3'), BDNF IIA (5'-TACTTCATCC AGTTCCACCAG-3' and 5' -CAAGTTGCCTTGTCCGT-3'), BDNF IIB (5'-AAGCTCCGGTTCCACCAG- ${ }^{\prime}$ and $5^{\prime}$-TGCTTCTTTCATGGG CG-3'), BDNF IIC (5'-GTGGTGTAAGCCGCAAAGA-3' and $5^{\prime}$-CGTG GACGTTTGCTTCTTTC- $\left.3^{\prime}\right), \beta$-actin ( $5^{\prime}$-GATCTGGCACCACACCTT CT- $3^{\prime}$ and $5^{\prime}$-GGGGTGTTGAAGGTCTCAAA-3'), GAPDH (5'-GTGG ACCTCATGGCCTACAT- $3^{\prime}$ and $5^{\prime}$-TGTGAGGGAGATGCTCAGTG$3^{\prime}$ ), and cyclophilin G ( $5^{\prime}$-AACTCCCAGCCTGCTTCATA- $3^{\prime}$ and $5^{\prime}-\mathrm{CT}$ GGATCTGGAAGGAGTTCG-3'). Primers for BDNF IIA, IIB, and IIC were previously described (Kobayashi et al., 2008; Gambazzi et al., 2010). Geometric averaging of $\beta$-actin, GAPDH, and cyclophilin G was used as internal control.

Immunoblotting and immunoprecipitation. Mice were killed by cervical translocation. Brains were removed and hippocampi were collected and frozen in liquid nitrogen. Hippocampi were lysed in $50 \mathrm{~mm}$ Tris $\mathrm{HCl}, 2$ mм EGTA, $10 \mathrm{~mm} \beta$-mercaptoethanol $0.1 \%(\mathrm{v} / \mathrm{v}), 10 \mu \mathrm{g} / \mathrm{ml}$ aprotinine, $10 \mu \mathrm{g} / \mathrm{ml}$ leupeptine, $1 \mathrm{~mm}$ sodium orthovavadate. Primary antibodies used in this study are as follows: anti-huntingtin (HU-4C8-As, Euromedex; D7F7, Cell Signaling Technology; P-HTT-S1201 and P-HTT-S1181) (Anne et al., 2007), anti- $\alpha$-tubulin (clone DM1A, Sigma-Aldrich), anti-BDNF (Santa Cruz Biotechnology), anti-CREB and anti-pCREB (phospho-Ser133, Cell Signaling Technology), anti-ERK and anti-pERK (p42/p44, phosphoThr202/Tyr204; Cell Signaling Technology). HRP-conjugated goat antimouse and anti-rabbit secondary antibodies were purchased from Jackson Immunoresearch Laboratories.

For immunoprecipitation, protein G-sepharose beads (SigmaAldrich) were incubated overnight with anti-HTT antibodies (4C8 or D7F7). Beads conjugated to $4 \mathrm{C} 8$ were incubated for $5 \mathrm{~h}$ with brain lysates, washed, and analyzed by immunoblotting.

Videomicroscopy experiments and analyses. Rat primary hippocampal neurons and $\mathrm{P} 0$ cortical primary neurons from mice of various genotypes were prepared as previously described (Anne et al., 2007) and electroporated with rat or mouse neuron Nucleofector (Amaxa), respectively. Neurons were electroporated as indicated with BDNF-mCherry (Zala et 
al., 2008); HTT-1301; HTT-1301-S1181A/S1201A; HTT-1301-S1181D/ S1201D constructs (Anne et al., 2007), and a siRNA (UUACUGUCUACUGGAUUCATT annealed with UGAAUCCAGUAGACAGUAATT) that targets a sequence outside the region coding the $N$-terminal 1301 aa of HTT.

One million neurons were plated in the upper chambers of dual microchambers coated with a mixture of poly-D-lysine $(0.5 \mathrm{mg} / \mathrm{ml})+$ laminin $(10 \mu \mathrm{g} / \mathrm{ml})$ and cultivated $5 \mathrm{~d}$ in neurobasal supplemented with $2 \% \mathrm{~B} 27,1 \%$ glutamax, and $1 \%$ penicillin/streptomycin.

Microchambers and neuronal plating were previously described (Zala et al., 2013). Briefly, silicon wafer obtained by photolithography was used to create the master with SU8 resin. The channels are $3 \mu \mathrm{m}$ high, $5 \mu \mathrm{m}$ wide, and $450 \mu \mathrm{m}$ long. Silicon elastomer with its curing agent was used (PDMS, Sylgard 184, Dow Corning) to create the devices. The microfluidic devices were then coated with poly-D-lysine $(0.5 \mathrm{mg} / \mathrm{ml})$ and laminin $(10 \mathrm{mg} / \mathrm{ml})$ overnight at $4^{\circ} \mathrm{C}$ and then washed three times with neuronal medium. One million neurons were plated in the cell body/proximal compartment of the chamber.

The microscope and the chamber were kept at $37^{\circ} \mathrm{C}$. Images were recorded with a $100 \times$ PlanApo N.A. 1.4 oil-immersion objective on a Leica DM IRBE microscope and collected every $200 \mathrm{~ms}$ in stream mode with $150 \mathrm{~ms}$ of exposure and a $2 \times 2$ binning using a Micromax camera (Ropper Scientific) controlled by MetaMorph software (Molecular Devices). Videos, kymographs, and analyses were generated with ImageJ software (http://rsb.info.nih.gov/ij/). Maximal projection was performed to identify the vesicles paths, which in our system corresponds to vesicle movements in axons. Kymographs and analyses were generated with the KymoToolBox, a home-made plug-in previously described (Zala et al., 2013).

Measure of transport-dependent BDNF release. Rat primary hippocampal neurons and P0 cortical primary neurons from mice of various genotypes were electroporated with a construct expressing a nontagged version of human BDNF (Zala et al., 2008). To measure transportdependent release, cells were depolarized (treatment for 20 min with neuronal culture medium with $28 \mathrm{~mm} \mathrm{KCl}, 30 \mathrm{~mm} \mathrm{CaCl}_{2}$ and $30 \mathrm{~mm}$ $\mathrm{NaCl}$ ) and the supernatant recovered (K1 fraction). After washings, neurons were incubated 30 min with normal neuronal culture medium, depolarized again and the new supernatant was recovered (K2 fraction). Finally, cells were lysed (L fraction) and the concentration of BDNF in all fractions was analyzed using BDNF Emax Immunoassay system (Promega).

BDNF immunoenzyme assays on hippocampi extracts. Hippocampi were lysed in $100 \mathrm{~mm}$ PIPES (pH 7), $500 \mathrm{~mm} \mathrm{NaCl}, 0.2 \%$ Triton X100, $0.1 \% \mathrm{NaN}_{3}, 2 \% \mathrm{BSA}, 2 \mathrm{~mm}$ EDTA, $10 \mu \mathrm{m}$ leupeptine, $0.3 \mu \mathrm{m}$ aprotinin, $1 \mu \mathrm{m}$ pepstatin, $200 \mu \mathrm{m}$ PMSF. The amount of BDNF was measured in supernatants and cell lysates using the BDNF Emax Immunoassay system (Promega) and expressed relative to the content of proteins in cells. BDNF levels in hippocampal extracts are reported in $\mathrm{ng} / \mathrm{mg}$ wet tissue weight.

Microtubule preparation. MTs were prepared from HeLa cells transfected with HTT-1301; HTT-1301-S1181A/S1201A and HTT-1301S1181D/S1201D. Cells were scrapped with PBS after $1 \mathrm{~h}$ treatment at $37^{\circ} \mathrm{C}$ with $1 \mu \mathrm{m}$ taxol. After a $5 \mathrm{~min}$ centrifugation at $1000 \times \mathrm{g}$, the pellet was dissociated in PM2G buffer (0.1 м PIPES, pH 6.8, 2 m glycerol, 5 mM $\mathrm{MgCl}_{2}, 2 \mathrm{~mm}$ EGTA) and diluted with the same volume of PM2G containing $0.4 \% \mathrm{NP} 40$. Another $5 \mathrm{~min}$ centrifugation at $1000 \times \mathrm{g}$ followed a $15 \mathrm{~min}$ incubation at $37^{\circ} \mathrm{C}$. The supernatant underwent a last centrifugation at $10,000 \times g(45 \mathrm{~min})$. The MTs containing pellet obtained was quickly washed with PM2G and dissolved in SDS buffer (31 mM Tris, $\mathrm{pH}$ $6.8,1 \%$ SDS, $5 \%$ glycerol). The supernatant was diluted by addition of an equal volume of $2 \times$ SDS buffer.

Immunofluorescence. Cells were transfected with BDNF-mCherry and HTT-1301; HTT-1301-S1181A/S1201A, and HTT-1301-S1181D/ S1201D. Cells were fixed $2 \mathrm{~min}$ in cold methanol with $2 \%$ paraformaldehyde. Immunofluorescence was performed for tubulin (mouse anti- $\alpha$ tubulin; clone DM1A, Sigma-Aldrich) and for the cherry-tag (rabbit anti-cherry; Recombinant Protein and Antibody Platform of the Institut Curie). Secondary antibodies, purchased from Jackson Immunoresearch Laboratories, were goat anti-mouse-A488 and anti-rabbit-A555. Cover- slips were mounted in $0.1 \mathrm{~g} / \mathrm{ml}$ Mowiol 4-88 (Calbiochem) in 20\% glycerol. Acquisitions of images were performed with a confocal Leica SP5 microscope. Analysis of BDNF vesicles on MTs was performed using ImageJ software (http://rsb.info.nih.gov/ij/).

Statistical analyses. Statview 4.5 software (SAS Institute) was used for statistical analysis. The criterion for statistical significance was set at $p<$ 0.05 . Data are expressed as mean \pm SEM.

\section{Results}

\section{Generation of $H d h^{S 1181 A / S 1201 A}$ and $H d h^{S 1181 D / S 1201 D}$ mice}

We used homologous recombination to generate knock-in mice in which the codons for serines at positions 1181 and 1201 of the gene encoding mouse HTT $(H d h)$ were replaced by codons for alanine $\left(H d h^{\text {S1181A/S1201A }}\right)$ or aspartic acid $\left(H d h^{\text {S1181D/S1201D }}\right)$ (Fig. 1A). Using expression of exogenous Cdk5, and inhibition of endogenous Cdk 5 by RNA interference or pharmacological approaches in primary cultured neurons, we have previously shown that these substitutions mimic the absence of phosphorylation and constitutive phosphorylation of HTT by Cdk5 on these sites (Anne et al., 2007). Genomic DNA from homozygous knock-in mice from each genotype was sequenced to confirm the replacement of the AGT codons by the GCT codons $\left(H d h^{S 1181 A / S 1201 A}\right)$ and by the GAT codons (Hdh $h^{S 1181 D / S 1201 D}$ ) (Fig. 1B). Wild-type, $H d h^{S 1181 A / S 1201 A}$ and $H d h^{S 1181 D / S 1201 D}$ mice can be discriminated by genotyping with specific primers recognizing sequences around the residual intronic LoxP sequence (Fig. 1C).

We evaluated the phosphorylation of HTT at serines 1181 and 1201. Lysates were prepared from adult cortices from the mice of the three genotypes, and HTT was immunoprecipitated and analyzed by immunoblotting with two phosphorylation statespecific polyclonal antibodies. Anti-P-HTT-S1181 specifically recognizes phosphorylated serine 1181 and anti-P-HTT-S1201 specifically recognizes phosphorylated serine 1201 (Anne et al., 2007). Both antibodies recognized HTT in wild-type mouse extracts showing that HTT is phosphorylated at these sites in the cortex of adult mouse (Fig. 1D). Neither anti-P-HTT-S1181 nor anti-P-HTT-S1201 detected HTT immunoprecipitated from $H d h^{\text {S1181A/S1201A }}$ and $H d h^{\text {S1181D/S1201D }}$ cortical extracts. This is in agreement with our previous findings that an N-terminal 1301 amino-acid fragment of wild-type HTT with S1181D/S1201D mutations is not recognized by the specific phosphoantibodies (Anne et al., 2007). Similar results were obtained using striatal and hippocampal extracts (data not shown). These results demonstrate that serines 1181 and 1201 are phosphorylated in the brain of adult wild-type mice, and are modified in $H d h^{\text {S1181A/S1201A }}$ and $H d h^{\text {S1181D/S1201D }}$ mice.

$\mathrm{Hdh}^{\text {S1181A/S1201A }}$ mice show reduced anxiety and depression-
related behavior
$H d h^{S 1181 A / S 1201 A}$ and $H d h^{S 1181 D / S 1201 D}$ mice are viable, fertile, and $H d h^{S 1181 A / S 1201 A}$ and $H d h^{S 1181 D / S 1201 D}$ mice are viable, fertile, and
do not show a motor phenotype (data not shown). To investigate their anxiety/depressive-like state, we applied standardized behavioral tests routinely used to evaluate the efficacy of antidepressive drugs on mice suffering from depression-related behavior (David et al., 2009). We tested the behavior of wild-type, $H d h^{S 1181 A / S 1201 A}$, and $H d h^{\text {S1181D/S1201D }} 12$-week-old mice in the open field paradigm (OF). $H d h^{S 1181 A / S 1201 A}$ mice spent more time than wild-type mice in the center, indicating less anxiety (Fig. $2 A) . H d h^{S 1181 D / S 1201 D}$ behaved in the same way as wild-type mice. The ratio of total distance moved in the center to total distance moved was higher for $H d h^{S 1181 A / S 1201 A}$ mice than wild-type and $H d h^{S 1181 D / S 1201 D}$ mice (Fig. 2A). This demonstrates that the absence of phosphorylation of HTT at serines 1181/1201 reduces 
A

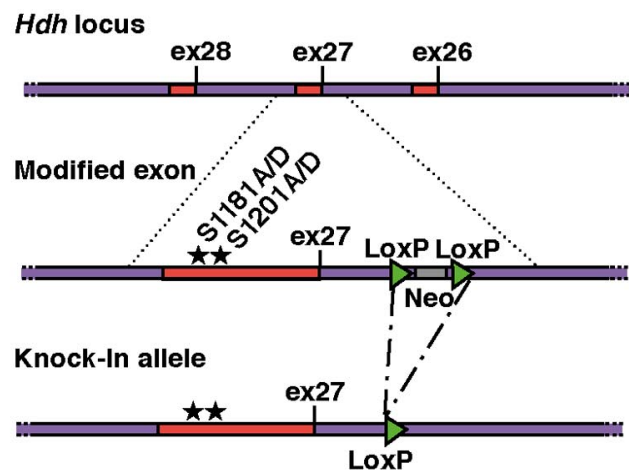

B

Wild-type

$H d h^{S 1181 A / S 1201 A}$

$H d h^{S 11810 / S 1201 D}$ position 1181


CGAGGAT

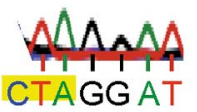

position 1201

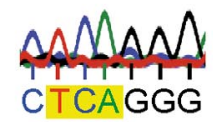

$\mathrm{man}$ CCGA GGG

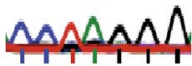
COCAGGC


D

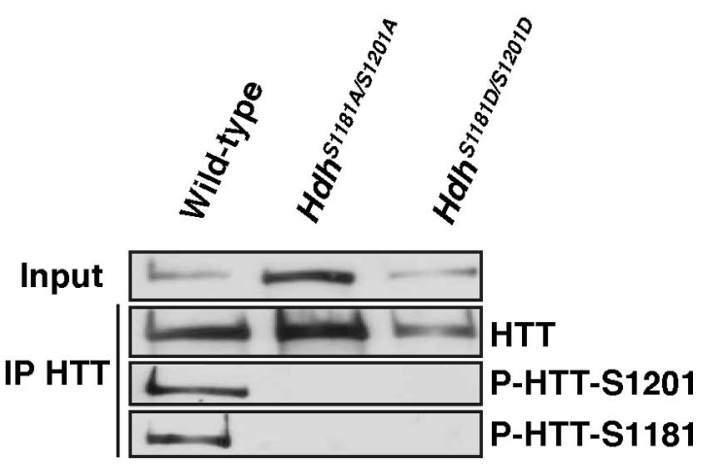

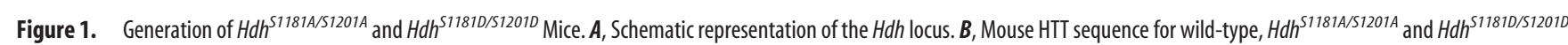
around the serines of interest. Data correspond to the noncoding strand. $C$, Representative PCR genotyping. Top, photo of a gel obtained after the migration of $P C R$ products. hetero, heterozygous; homo, homozygous. Bottom, primers location and size of PCR products obtained for wild-type, $H d h^{\text {S1181A/S1201A }}$ on the left and Hdh ${ }^{S 1181 D / S 1201 D}$ on the right. D, HTT (4C8) immunoprecipitates (IP) of extracts from wild-type, $H d h^{S 1181 A / S 1201 A}$ and $H d h^{S 1181 D / S 1201 D}$ cortices are immunoblotted using anti-HTT (4C8), anti-P-HTT-S1181, and anti-P-HTT-S1201 antibodies.

the anxiety-like phenotype in mice without affecting locomotor activity. Similarly, in the novelty suppressed feeding test (NSF), the latency to feeding was shorter for $H d h^{S 1181 A / S 1201 A}$ mice than wild-type and $H d h^{S 1181 D / S 1201 D}$ mice (Fig. $2 B$ ), with no cofounding feeding effect (right graph).

We also evaluated the grooming behavior, that is an index of a depressed-like state (Surget et al., 2008). After a 10\% sucrose solution was sprayed on the mouse snout, $H d h^{S 1181 A / S 1201 A}$ spent more time grooming than wild-type and $H d h^{S 1181 D / S 1201 D}$ mice (Fig. 2C).

There was no difference between female and male behavior, for each genotype, in any of the behavioral tests. Collectively, these various findings show that abolition of HTT phosphorylation at S1181/S1201 reduces both anxiety and depression-related behavior in mice.

\footnotetext{
Ablation of HTT phosphorylation at S1181/S1201 promotes survival and maturation of newborn neurons in the hippocampal dentate gyrus

The hippocampus is important for the regulation of mood disorders and hippocampal neurogenesis is involved, at least in part, in the regulation of the response to antidepressants (for review, see Samuels and Hen, 2011). We thus focused our attention on neurogenesis in the dentate gyrus of the hippocampus in 14-week-
}

old animals that had performed the behavioral tests. We first estimated the number of proliferating cells using Ki67 and apoptotic cell death using a TUNEL assay. We did not observe any differences in the numbers of proliferating and apoptotic cells in the dentate gyrus between the different genotypes (data not shown) (Fig. 3A). We next assessed the survival rate of newly generated neurons by labeling with the thymidine analog BrdU (Fig. 3B). The number of newborn cells surviving 3 weeks after BrdU administration in the dentate gyrus was higher in the hippocampi of $H d h^{S 1181 A / S 1201 A}$ than wild-type and $H d h^{S 1181 D / S 1201 D}$ animals.

We then quantified the number of doublecortin (DCX)positive neurons: DCX is produced by neuronal progenitors and immature neurons and is a marker for adult neurogenesis. We found no differences between the quantities of new immature DCX-positive neurons produced in the three genotypes (Fig. 3C). We then analyzed the DCX-positive neurons according to the degree of complexity of their dendrites (Orvoen et al., 2011) (Fig. $3 D$ ). There were more DCX-positive neurons with quinary dendrites and a higher maturation index in $H d h^{S 1181 A / S 1201 A}$ than wild-type and $H d h^{S 1181 D / S 1201 D}$ animals. Thus, to further examine this latest effect, we performed a Sholl analysis to study dendritic arborization of DCX-positive neurons (Fig. 3E). Sholl analysis quantifies dendritic complexity and growth according to the dis- 
tance from the soma by considering concentric circles around the soma (Wang et al., 2008; Sahay et al., 2011). The numbers of intersections at $60-140 \mu \mathrm{m}$ from the soma (left graph) and dendritic length (right graph) were both higher in $H d h^{S 1181 A / S 1201 A}$ than wild-type and $H d h^{S 1181 D / S 1201 D}$ mice.

These data show that the presence of a nonphosphorylatable HTT at positions S1181/S1201 is associated with greater neurogenesis due to increased survival and dendritic maturation of the newborn neurons in the dentate gyrus of the adult hippocampus.

\section{BDNF levels and induced-signaling are increased in the hippocampus of $H_{d h}{ }^{\text {S1181A/S1201A }}$ mice}

Given that the absence of phosphorylation of HTT at S1181/1201 leads to increased maturation and survival of hippocampal neurons, we evaluated BDNF levels and signaling in the hippocampus of mice of the three genotypes. Indeed, BDNF is a key factor specifically regulating dendritic maturation and survival of newly generated neurons in the dentate gyrus of the hippocampus (Krishnan and Nestler, 2008). We thus assayed BDNF protein by ELISA in hippocampal extracts (Fig. 4A). Total BDNF protein abundance, including both pro-BDNF and mature BDNF, was significantly greater in $H d h^{S 1181 A / S 1201 A}$ than wild-type and $H d h^{S 1181 D / S 1201 D}$ mice. We used immunoblotting to discriminate between pro-BDNF and mature BDNF in hippocampal extracts of wildtype, $H d h^{S 1181 A / S 1201 A}$ and $H d h^{S 1181 D / S 1201 D}$ mice (Fig. $4 B$ ). The mature-BDNF/pro-BDNF ratio was very much higher in $H d h^{S 1181 A / S 1201 A}$ hippocampal protein extracts.

To determine whether BDNF production was efficiently converted into signaling, we studied the mitogen-activated protein kinase (MAPK) pathway. This pathway is elicited by BDNF and plays a role in adult neurogenesis (Cohen and Greenberg, 2008). Binding of BDNF to its receptor, the tropomyosin-related kinase receptor type $B(\operatorname{TrkB})$, results in the sequential activation of Erk and the cAMP responsive element binding protein (CREB). We therefore used immunoblotting to evaluate the levels of total and activated Erk and CREB in hippocampal extracts from the three mouse lines (Fig. $4 C$ ). The ratio of active to total amounts of these targets was significantly higher in $H d h^{\text {S1181A/S1201A }}$ than wild-type and $H d h^{S 1181 D / S 1201 D}$ mouse lines. Therefore, BDNF production and activation of Erk and CREB are elevated in the hippocampus of $H d h^{\text {S1181A/S1201A }}$ mice.

\section{Neuronal activity-induced $b d n f$ transcript IV is elevated in} the hippocampus of $\mathrm{Hdh}^{\mathrm{S1181A} / \mathrm{S1201A}}$ mice

We investigated the mechanisms by which HTT phosphorylation status at S1181/S1201 affects on BDNF. BDNF expression is controlled by multiple promoters that are used in activity-dependent and tissue-specific manners (for review, see Cohen and Greenberg, 2008; Zheng et al., 2012). Interestingly, wild-type huntingtin acts in the cytoplasm of neurons to regulate the availability of

\section{Open field}
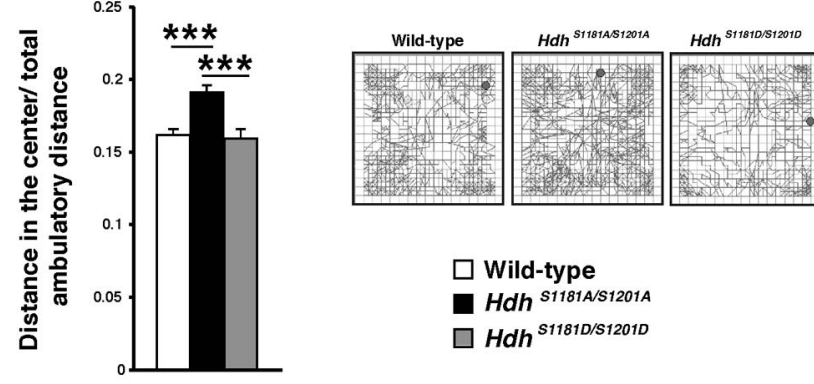

C Splash test
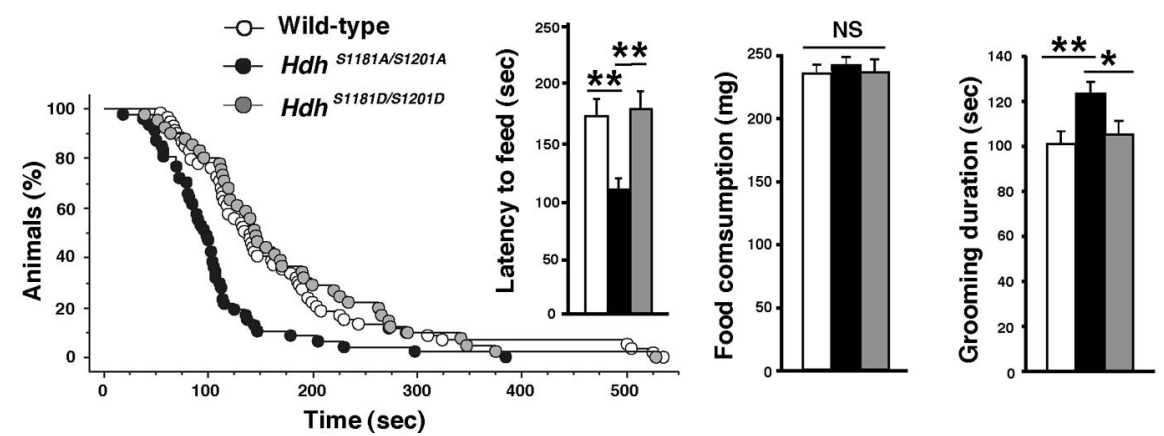

Figure 2. $\quad H d h^{S 1181 A / S 1201 A}$ mice show reduced anxiety/depression-like behavior compared with $H d h^{511810 / 51201 D}$ and wild-type Representative trajectories followed by a mouse of each genotype during one session are shown in the three squares. All graphs: $n>40$ mice per group; Values plotted are mean \pm SEM. Significant ANOVAs were followed up with Fisher's PLSD test: NS, not significant; ${ }^{*} p<0.05,{ }^{* *} p<0.01$, and ${ }^{* * *} p<0.001$.

repressor element-1 transcription factor/neuron restrictive silencer factor (REST/NRSF) to its nuclear neuron restrictive silencer element (NRSE) binding site on BDNF promoter II (Zuccato et al., 2003). We thus evaluated the amounts of $b d n f$ exon IIA, IIB, and IIC transcripts in the hippocampus of $H d h^{\text {S1181A/S1201A }}, H d h^{\text {S1181D/S1201D }}$, and wild-type mice by quantitative PCR (Fig. 4D). The expression of these transcripts was similar among the three genotypes.

We next assessed the expression of a neuronal activityinduced $b d n f$ transcript (promoter IV). Indeed, BDNF exon IV transcription is up-regulated by BDNF itself and by CREB through a calcium regulatory element present in this region (Cohen and Greenberg, 2008; Zheng et al., 2012). $H d h^{S 1181 A / S 1201 A}$ exhibited a higher expression of neuronal activity-induced $b d n f$ than the $H d h^{\text {S1181D/S1201D }}$ and wild-type animals (Fig. 4D). Thus, although BDNF transcripts levels are increased in $H d h^{S 1181 A / S 1201 A}$ animals, the phosphorylation status of wild-type HTT does not affect its function as a transcription regulator for the $b d n f$ promoter. Rather, our data suggest that in $H d h^{\text {S1181A/S1201A }}$ mice the increased BDNF production and signaling leads to a subsequent increased activitydependent BDNF transcription.

\section{Unphosphorylated HTT increases BDNF transport} and release

Another key event in the regulation of BDNF signaling is its MTbased vesicular transport, a process facilitated by HTT (Gauthier 
A



\section{$\square$ Wild-type}

Hdh S1181A/S1201A

$\square H d h^{511810 / 512010}$

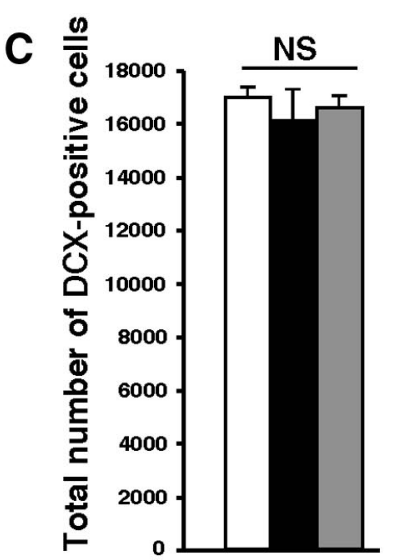

\section{B}


\section{Survival protocol}
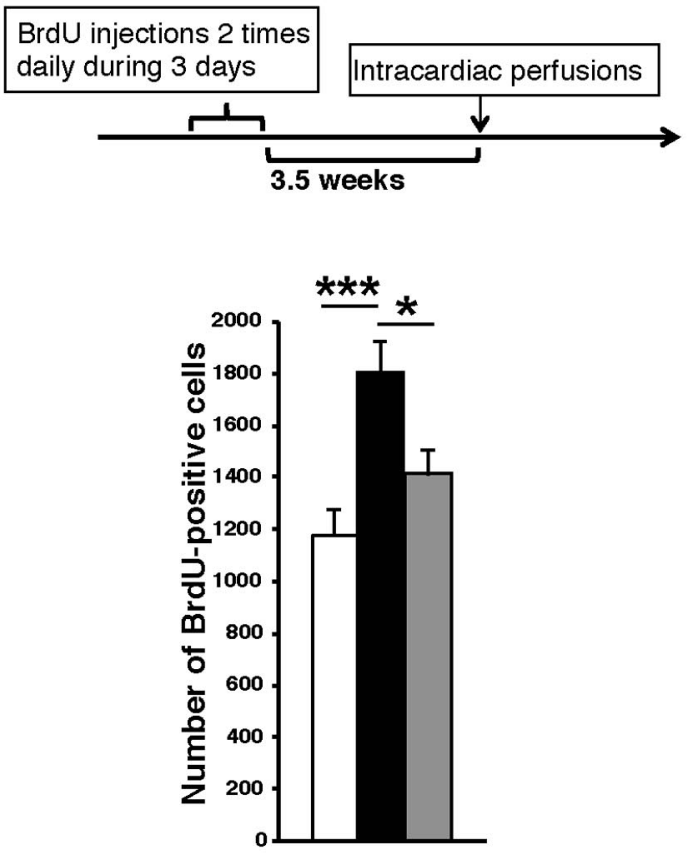

D


$\mathbf{E}$
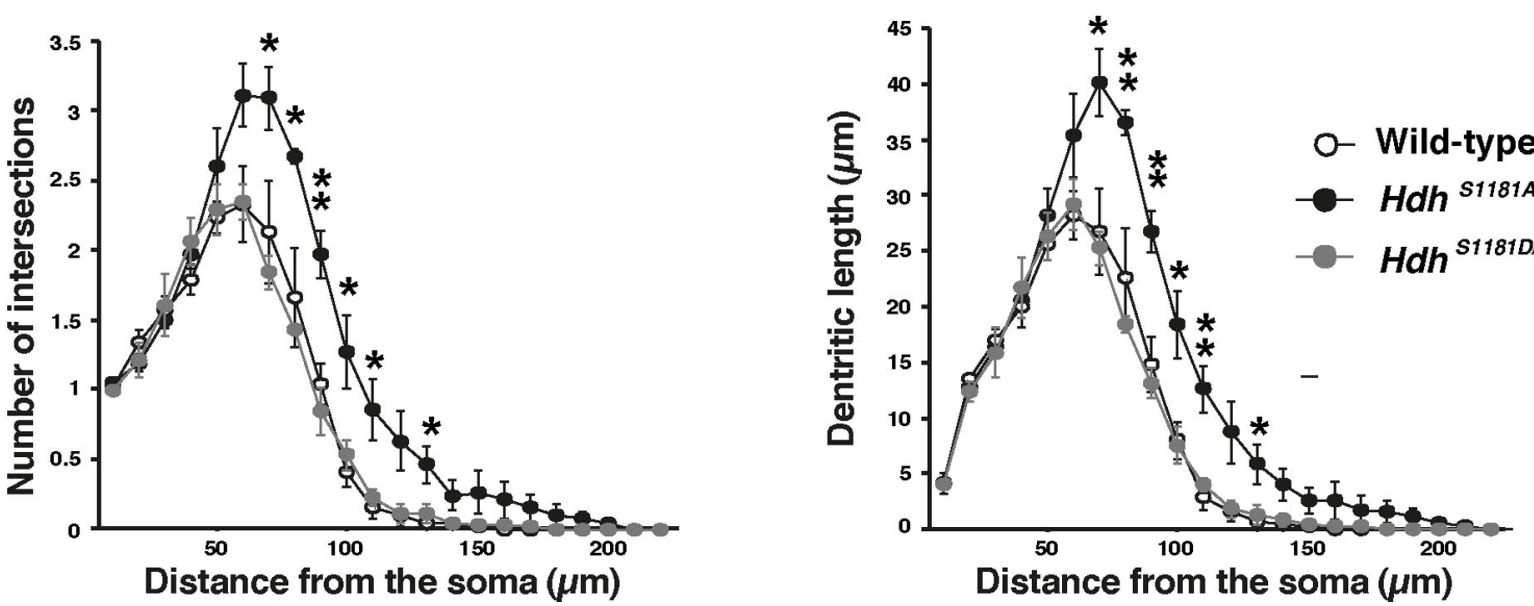

Figure 3. The behavioral effects observed in mice expressing unphosphorylated HTT are mediated by a neurogenesis-dependent mechanism. $\boldsymbol{A}$, Quantification of the total number of TUNELpositive cells in the dentate gyrus per mouse $(n=3)$ from each genotype (ANOVA $\left.F_{(2.6)}=0.833 ; p=0.4793\right)$. B, Protocol used to measure neuronal survival and representative immunostaining

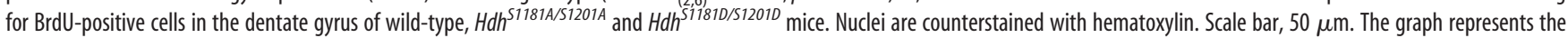
quantitative assessment of the mean total number of BrdU-positive cells in the dentate gyrus per mouse $(n \geq 6)$ from each genotype (ANOVA $\left.F_{(2,17)}=7.700 ;{ }^{* *} p<0.01\right) . C$, Q Quantification of the mean total number of DCX-positive neurons in the dentate gyrus per mouse $(n=4)$ from each genotype (ANOVA $\left.F_{(2,9)}=0.297 ; p=0.7498\right)$. D, lllustration of a DCX-positive (Figure legend continues.) 
et al., 2004; Caviston et al., 2007). We therefore tested the consequences of phosphorylating HTT at S1181/S1201 on BDNF trafficking by expressing constructs encoding the $N$-terminal 1301 aa of wild-type HTT with either intact S1181/S1201, or S1181A/ 1201A, or S1181D/S1201D mutations (HTT-1301; HTT-1301S1181A/S1201A; HTT-1301-S1181D/S1201D) (Fig. 5A). These constructs contain the domains required for the interaction between HTT and molecular motors, and increase axonal transport when expressed in neurons (Caviston et al., 2007; Pardo et al., 2010). To ensure that the observed effects were due solely to the ectopic expression of the various constructs and their different S1181 and S1201 status, we used primary cultures of rat hippocampal neurons in which endogenous HTT was silenced using small interfering RNA (siRNA). The expression of these constructs was not affected by the siRNA used because it targets a different portion of the HTT gene. Neurons were also coelectroporated with BDNF-mCherry and plated in microchambers derived from a previously described microfluidic culture platform (Taylor et al., 2005). Our device contains channels that are $5 \mu \mathrm{m}$ wide, $450 \mu \mathrm{m}$ long, and $3 \mu \mathrm{m}$ high, and allows CNS axons to grow into a fluidically isolated environment free of any chemo attractants or trophic factors. Embryonic rat cortical neurons can extend long processes into the channels, but only axons can reach the distal chamber located $450 \mu \mathrm{m}$ away from the proximal chamber containing the cell bodies and most of the dendrites. After $4 \mathrm{~d}$ of culture in vitro, we quantified axonal transport in the distal part of the microchamber as anterograde and retrograde according to their direction relative to the cell bodies.

Both anterograde and retrograde velocities of BDNF vesicles were higher for HTT unphosphorylated at S1181/S1201 than for HTT with intact serines or S1181D/S1201D substitutions (Fig. $5 A$ ). We next used a BDNF release assay that is strictly dependent upon BDNF transport to test the ability of neurons to release BDNF (Gauthier et al., 2004). BDNF release was measured by ELISA after two successive KCl-induced depolarizations (K1 and $\mathrm{K} 2$ ). The first depolarization allowed the release of the readily releasable pool at the membrane, and the second that of the pool reconstituted through MT-based transport. K2 is thus a measure of transport-dependent release. Neurons were coelectroporated with siRNA targeting endogenous HTT, BDNF, and the constructs encoding HTT-1301, HTT-1301-S1181A/S1201A, or HTT-1301-S1181D/S1201D. The transport-dependent release by neurons expressing unphosphorylatable HTT was higher than that by neurons expressing HTT or HTT-S1181D/S1201D (Fig. $5 B)$. Thus, BDNF transport and subsequent release are increased when HTT is unphosphorylatable at S1181/S1201.

We then evaluated BDNF transport and release in more physiological conditions. Primary cultures of newborn cortical neurons from wild-type, $H d h^{\text {S1181A/S1201A }}$ and $H d h^{\text {S1181D/S1201D mice }}$ were electroporated with BDNF-mCherry and the dynamics of

\footnotetext{
$\leftarrow$

(Figure legend continued.) neuron with quinary dendrites. White arrowheads point to dendritic nodes. Scale bar, $10 \mu \mathrm{m}$. Histograms show the quantification of the mean total number of neurons with quinary dendrite per mouse $(n \geq 3)$ from each genotype $\left(\operatorname{ANOVA} F_{(2,8)}=8.848\right.$; ${ }^{* *} p<0.01$ ), and the maturation index (ANOVA $F_{(2,8)}=6.211 ;{ }^{*} p<0.05$ ). The maturation index is a normalization of the number of neurons with quinary dendrites over the total number of DCX-positive neurons. $\boldsymbol{E}$, Sholl analysis of DCX-positive neurons. The graphs indicate the number of intersections (left graph) and the dendritic length (right graph) according to the distance from the soma for each condition ( $n=3$ per group). All graphs: Values plotted are mean \pm SEM. Significant ANOVAs were followed up with Fisher's PLSD test; ${ }^{*} p<0.05$, ${ }^{* *} p<$ 0.01 , and ${ }^{* * *} p<0.001$.
}

BDNF-mCherry-containing vesicles studied as described for Figure $5 A$ (Fig. $5 C$ ). When endogenous HTT was not phosphorylated, transport of BDNF increased: anterograde and retrograde velocities of BDNF vesicles were higher in $H d h^{S 1181 \mathrm{~A} / \mathrm{S} 1201 \mathrm{~A}}$ neurons than controls, and the percentage of vesicles pausing was lower. Kymographs generated from the video recordings illustrated these findings (Fig. 5D). We also investigated the subsequent release of BDNF upon mutation of endogenous HTT and observed greater transport-dependent BDNF release by $H d h^{\text {S1181A/S1201A }}$ neurons than wild-type and $H d h^{\text {S1181D/S1201D }}$ neurons (Fig. 5E).

These experiments demonstrate that BDNF transport and subsequent release are significantly modified by the S1181/S1201 phosphorylation status of HTT.

\section{Unphosphorylated HTT increases the attachment of motor proteins and BDNF vesicles to microtubules}

HTT promotes BDNF MT-dependent transport by scaffolding motor proteins on MTs (Gauthier et al., 2004; Colin et al., 2008). We assessed whether the phosphorylation status of HTT affects the interactions between dynein/dynactin and MTs. We fractionated the subcellular components of HeLa cells expressing HTT-1301, HTT-1301-S1181A/S1201A, or HTT-1301-S1181D/ S1201D, and obtained MT and cytosolic fractions (Fig. 6A). Immunoblotting analyses (left) and corresponding quantifications (right) revealed that the levels of HTT, the p150 Glued subunit of dynactin, and dynein were higher in the MT fraction of cells expressing HTT-1301-S1181A/S1201A than in MT fractions of cells expressing HTT-1301 or HTT-1301-S1181D/S1201D. HTT associates with huntingtin-associated protein-1 (HAP1), and HAP1 associates with $\mathrm{p} 150^{\text {Glued }}$ and the light chain of kinesin- 1 to stimulate MT-based transport (Engelender et al., 1997; Gauthier et al., 2004; McGuire et al., 2006). However, the levels of HAP1 did not vary in the different MT fractions (data not shown).

We also coexpressed constructs encoding BDNF with HTT1301 or HTT-1301-S1181A/S1201A or HTT-1301-S1181D/ S1201D (Fig. 6B). We immunostained the cells for $\alpha$-tubulin and $\mathrm{BDNF}$, and quantified the number of BDNF vesicles on MTs. The percentage of vesicles attached to MTs was significantly higher in cells expressing HTT-1301-S1181A/S1201A than in cells expressing HTT-1301 or HTT-1301-S1181D/S1201D (Fig. 6B).

Together, these results provide strong evidence that the presence of S1181/S1201 unphosphorylatable HTT leads to the recruitment of dynein/dynactin and BDNF vesicles to the MTs.

\section{Discussion}

The physiological functions of HTT in adulthood have been largely overlooked. The only study specifically addressing this aspect involved conditional loss of HTT from the postnatal mouse forebrain and testis, and led to a degenerative neuronal phenotype and sterility (Dragatsis et al., 2000). Here, by studying the regulatory roles of HTT phosphorylation at S1181/1201, we show that HTT affects neurogenesis in the dentate gyrus of the hippocampus and also anxiety and depression-like behavior in adult mouse. Our study further supports the idea that HTT has essential biological functions in the adult brain, which are perturbed during HD progression leading to specific pathological manifestations in patients.

Functions in neuronal transcription, intracellular dynamics, ciliogenesis and division have been attributed to HTT (Gauthier et al., 2004; Cattaneo et al., 2005; Caviston et al., 2007; Godin et al., 2010; Keryer et al., 2011). Therefore, HTT is implicated in central cellular pathways important in development, in adults, and in disease pro- 
A

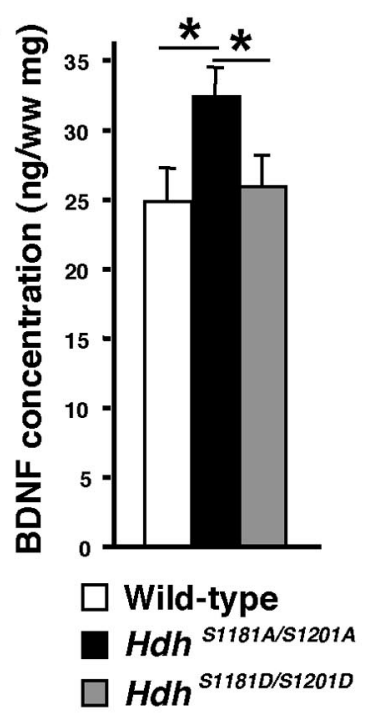

B


C
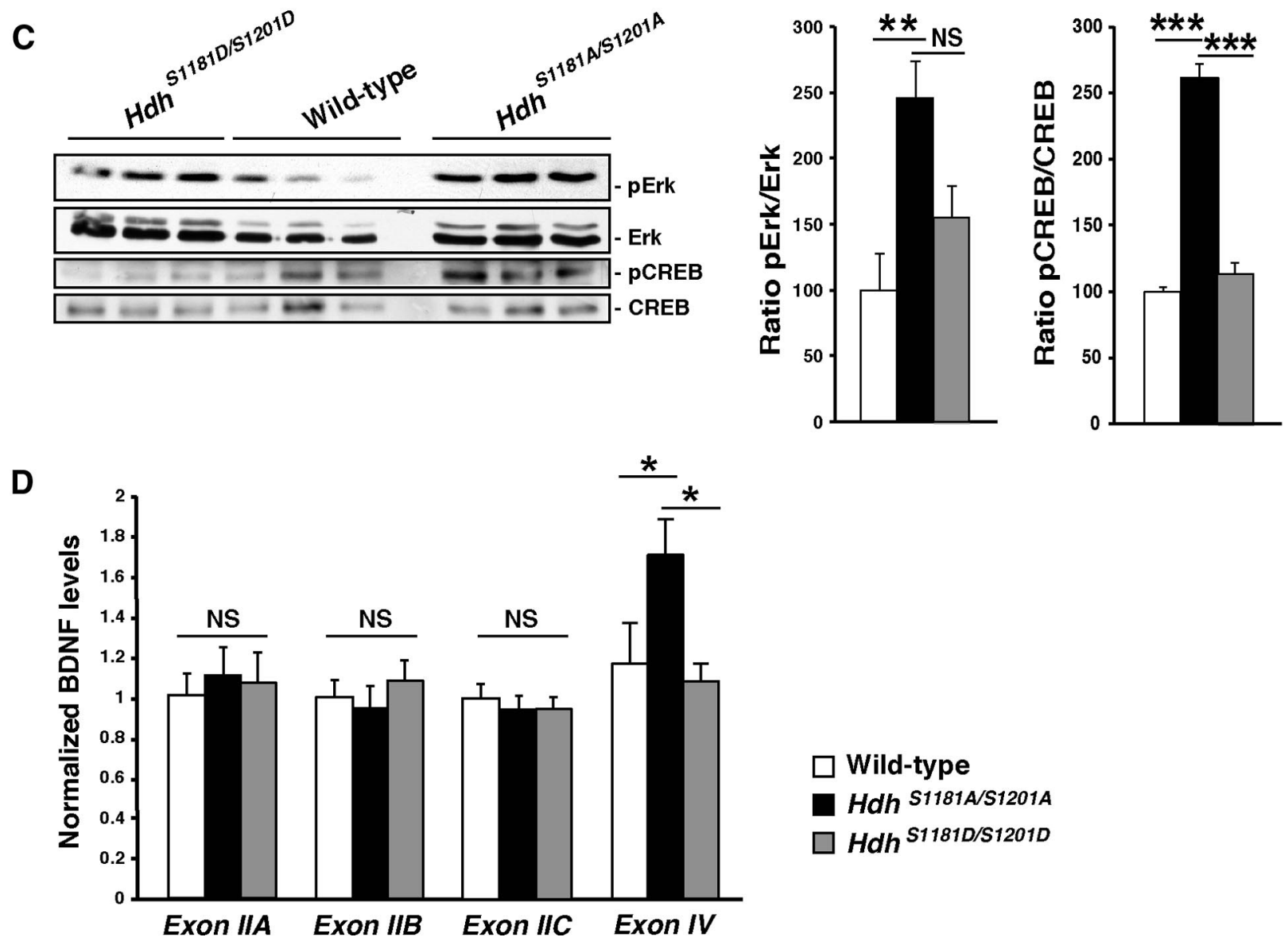

$\square$ Wild-type

Hdh S1181A/S1201A

$H d h^{S 1181 D / S 1201 D}$

Figure 4. BDNF expression and signaling is increased in $H d h^{S 1181 A / S 1201 A}$ hippocampi. $A$, BDNF total protein levels in the hippocampus of wild-type, $H d h^{S 1181 A / S 1201 A}$ and $H d h^{S 11810 / 512010}$ mice are measured by BDNF immunoenzyme assays $\left(n \geq 13\right.$ hippocampi per group; $\left.A N O V A F_{(2,39)}=3.242 ;{ }^{*} p<0.05\right)$. $B$, Hippocampal extracts from mice of the different genotypes were analyzed by immunoblotting for the presence of BDNF. The graph represents the quantitative assessment of the ratio of mature-BDNF/pro-BDNF $\left(n=3\right.$ hippocampi per group; ANOVA $_{(2,6)}=12.500 ;{ }^{* * *} p<$ 0.01). C, Hippocampal extracts from mice ( $n=3$ hippocampi per group) of the different genotypes are analyzed by immunoblotting for the presence of phosphorylated-Erk (phospho-Ser133-Erk, pErk), Erk, phosphorylated-CREB (phospho-Thr202/Tyr204-CREB, pCREB), and CREB. The graphs represent the quantitative assessments of the ratio of activated Erk/CREB over total Erk/CREB (pErk/Erk ratio: $A N O V A F_{(2,6)}=7.410 ;{ }^{*} p<0.05$, and $\mathrm{pCREB} / \mathrm{CREB}$ ratio: $\left.\mathrm{ANOVAF}(2,5)=126.737 ;{ }^{* * *} p<0.001\right) . \boldsymbol{D}$, bdnf exon IIA, IIB, IIC, and IV transcripts levels as determined by quantitative PCR analysis $\left(n \geq 6\right.$ hippocampi per group; exon IIA: ANOVA $F_{(2,15)}=0.137, p=0.8730$; exon IIB: ANOVAF $F_{(2,15)}=0.47, p=0.6336$; exon IIC: ANOVA $_{(2,15)}=0.257, p=0.7769 ;$ exon IV: $A N O V A$ $\left.F_{(2,17)}=4.365, p=0.0295\right)$. All graphs, Values plotted are mean \pm SEM. Significant ANOVAs were followed up with Fisher's PLSD test; ${ }^{*} p<0.05,{ }^{* *} p<0.01$ and ${ }^{* * *} p<0.001$.

cesses. The molecular biology of HTT is complex, but consistent with HTT being a scaffold protein that coordinates diverse events at the cellular level. For instance, HTT binds to the dynein intermediate chain and to the $150^{\text {Glued }}$ subunit of dynactin via HAP1 to regulate the intracellular trafficking of various organelles (Engelender et al., 1997; Li et al., 1998; Gauthier et al., 2004; Caviston et al., 2007). Phosphorylation of S421 of HTT regulates the assembly of this complex, specifically favoring anterograde transport (Colin et al., 
A BDNF axonal transport

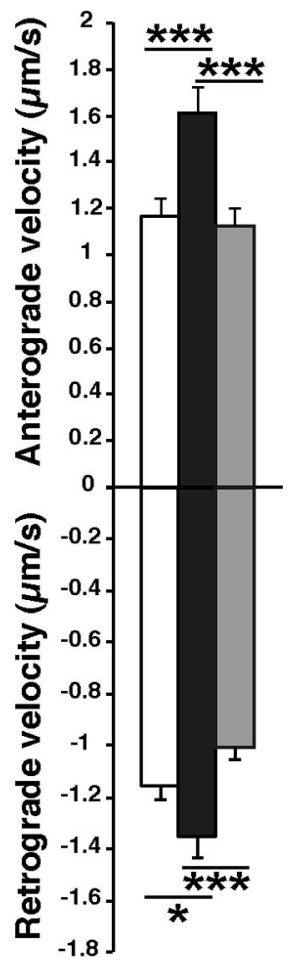

B BDNF release
C

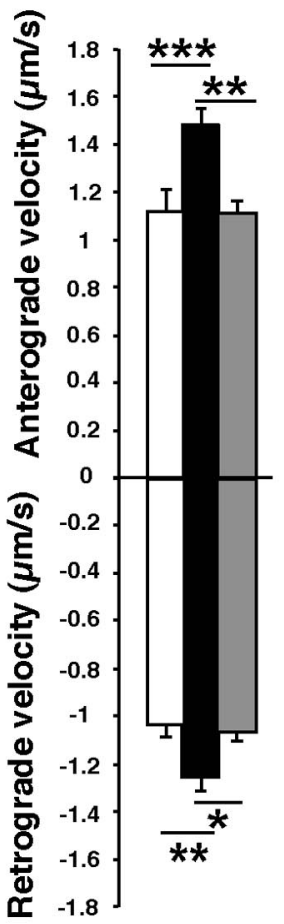

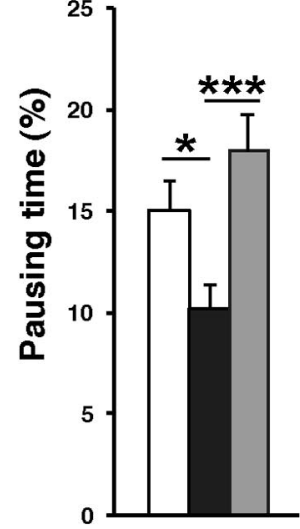

HTT + siHTT + BDNF-mCherry

HTT-AA + siHTT + BDNF-mCherry

HTT-DD + siHTT + BDNF-mCherry

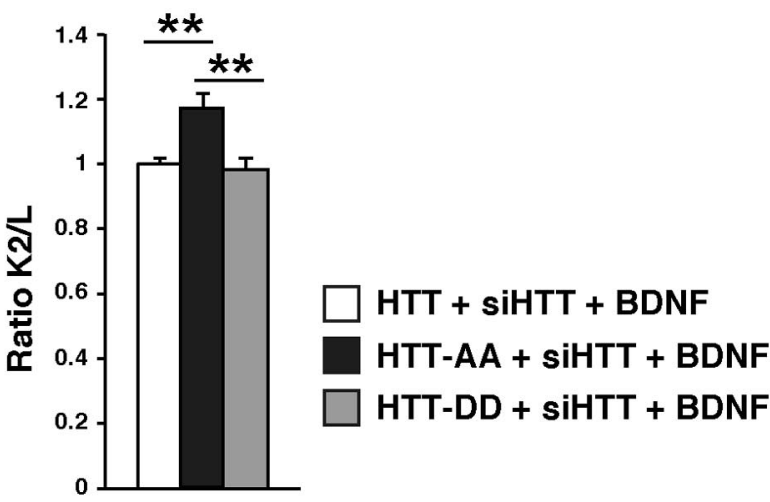

E BDNF release

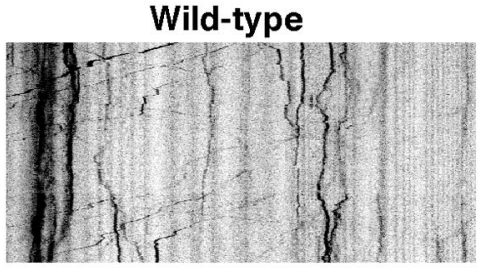

$H d h^{S 1181 A / S 1201 A}$

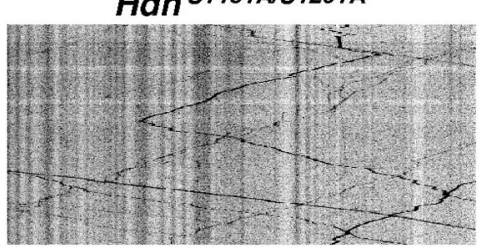

$H d h^{S 11810 / S 1201 D}$



$\mu \mathrm{m}$

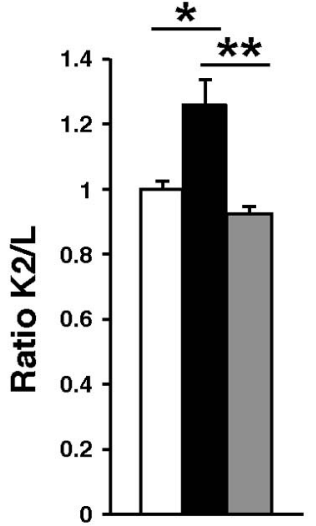

$\square$ Wild-type + BDNF

Hdh S1181AS1201A + BDNF

$H d h^{S 1181 D / S 1201 D}+$ BDNF

$\square$ Wild-type + BDNF-mCherry

Hdh S1181A/S1201A + BDNF-mCherry

$H d h^{511810 / S 1201 D}+$ BDNF-mCherry

Figure 5. S1181A/S1201A-HTT promotes microtubule-based BDNF transport and release. $A$, Anterograde and retrograde transports of BDNF-mCherry-containing vesicles are analyzed in primary cultures of rat hippocampal neurons coelectroporated as indicated with constructs expressing the first N-terminal 1301 aa of wild-type HTT with HTT-1301 (HTT), HTT-1301-S1181A/S1201A (HTT-AA), or HTT-1301-S1181D/S1201D (HTT-DD), siRNA targeting HTT (siHTT) and BDNF-mCherry (vesicles number: $n \geq 42$ for each condition; anterograde velocity: ANOVA $F_{(2,132)}=9.376$; ${ }^{* * *} p<0.001$; retrograde velocity: ANOVA $F_{(2,132)}=7.613 ;{ }^{* * *} p<0.001$ and pausing time: ANOVA $\left.F_{(2,132)}=6.443 ;{ }^{* *} p<0.01\right)$. Data were obtained from three independent experiments. $B$, Transport-dependent BDNF release is evaluated after two KCl-induced depolarizations in hippocampal neurons coelectroporated as indicated with siRNA targeting HTT (siHTT) and HTT-1301 (HTT), or HTT-1301-S1181A/S1201A (HTT-AA) or HTT-1301-S1181D/S1201D (HTT-DD) and BDNF. Release is expressed as a K2/L (L, lysate) ratio (ANOVA $\left.F_{(2,6)}=11,390 ;{ }^{* *} p<0.01\right)$. Data were obtained from three independent experiments. $C$, Anterograde and retrograde transports of BDNF-mCherry-containing vesicles are analyzed in primary cultures of cortical neurons (Figure legend continues.) 
A



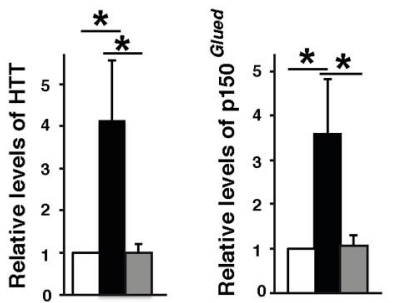

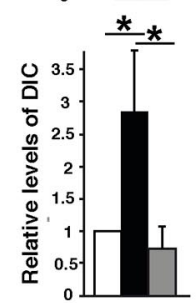

B


$\square$ HTT + BDNF-mCherry

$\square$ HTT-AA + BDNF-mCherry $\square$ HTT-DD + BDNF-mCherry

Figure 6. The S1181/S1201 phosphorylation status of HTT regulates motors and BDNF vesicles attachment to microtubules. $A$, MT fractionation of HeLa cells expressing HTT-1301 (HTT), HTT-1301-S1181A/S1201A (HTT-AA), or HTT-1301-S1181D/S1201D (HTT-DD). Samples are analyzed by immunoblotting for the presence of HTT, p156 Glued, and dynein (DIC, dynein intermediate chain). The graphs represent the ratios of $\mathrm{HTT}\left(\operatorname{ANOVAF}_{(2,12)}=4.335 ;{ }^{*} p<0.05\right), \mathrm{p} 150^{\text {Glued }}\left(\operatorname{ANOVAF}_{(2,12)}=4.372 ;{ }^{*} p<0.05\right)$, and DIC to tubulin (ANOVA $F_{(2,12)}=4.028 ;{ }^{*} p<0.05$ ). Values refer to band densities. $S$, supernatant; $P$, pellet corresponding to the MT-enriched fraction. Data are from five independent experiments. $\boldsymbol{B}$, Cells express HTT-1301 (HTT), HTT-1301-S1181A/ S1201A (HTT-AA), or HTT-1301-S1181D/S1201D (HTT-DD) and BDNF-mCherry. Cells are immunostained for the presence of BDNF (red) and $\alpha$-tubulin (green). Scale bar, $5 \mu \mathrm{m}$ and for the magnification: $1 \mu \mathrm{m}$. The graph represents the quantifications of BDNF-mCherry vesicles localized on MTs for each conditions $\left(\operatorname{ANOVAF}_{(2,106)}=3234 ;{ }^{*} p<0.05\right)$. Data are from three independent experiments. All graphs, Values plotted are mean \pm SEM. Significant ANOVAs were followed up with Fisher's PLSD test; ${ }^{*} p<0.05$, ${ }^{* *} p<0.01$, and ${ }^{* * *} p<0.001$.

2008). We found no difference in the phosphorylation status of S421 in hippocampal protein extracts from wild-type, $H d h^{\text {S1181A/S1201A }}$, and $H d h^{\text {S1181D/S1201D }}$ animals (data not shown). This is in agreement with the fact that the regulatory

$\leftarrow$

(Figure legend continued.) from wild-type, $H d h^{51181 A / / 1201 A}$ and $H d h^{511810 / 512010}$ mice elec-


$H d h^{511810 / 512010} n=32$; anterograde velocity: $\operatorname{ANOVAF}_{(2,134)}=8.906 ;{ }^{* * * *} p<0.001$; retrograde velocity: $\operatorname{ANOVA} F_{(2,134)}=4.735 ;{ }^{*} p<0.05$ and pausing time: $\operatorname{ANOVAF} F_{(2,134)}=4.872$; $\left.{ }^{* *} p<0.01\right)$. Data were obtained from three independent experiments. $\boldsymbol{D}$, Representative kymographs of BDNF-mCherry-containing vesicles dynamics. $\boldsymbol{E}$, Transport-dependent BDNF release is evaluated after two $\mathrm{KCl}$-induced depolarizations of cultured cortical neurons from wild-type, $H d h^{51181 A / 51201 A}$, and $H d h^{511810 / 512010}$ mice electroporated with BDNF. Release is expressed as a $\mathrm{K} 2 / \mathrm{L}$ ratio $\left(\operatorname{ANOVA} F_{(2,6)}=10.311 ;{ }^{*} p<0.05\right)$. Data were obtained from three independent experiments. All graphs, Values plotted are mean \pm SEM. Significant ANOVAs were followed up with Fisher's PLSD test; ${ }^{*} p<0.05,{ }^{* *} p<0.01$, and ${ }^{* * *} p<0.001$.



effect of S1181/S1201 applies to both anterograde and retrograde transport. This suggests that phosphorylating S421 and S1181/S1201 have differential consequences for the function of HTT as a dynein/dynactin scaffold.

Typical symptoms of HD include personality changes, cognitive deterioration, involuntary choreiform movements, and hypokinesia. Psychiatric disturbances and personality changes are among the first symptoms to appear in patients. Depression is prevalent, and is often manifest before the diagnosis of the disease (Kirkwood et al., 2001; Duff et al., 2007). Duff et al. (2007) showed that nondiagnosed HD carriers have greater levels of depression than expansion-negative at-risk individuals. In parallel, several studies have investigated how adult neurogenesis is affected in the brains of HD mouse models (for review, see Gil-Mohapel et al., 2011). The functional consequences of these alterations have not been directly addressed, but it is tempting to speculate that a compromised neurogenic process might contribute, at least in part, to the occurrence of depression in these models. Adult neurogenesis in two locations has been studied: the dentate gyrus of the hippocampus and the subventricular zone (SVZ) adjacent to the lateral ventricles. Defects in the proliferation of progenitors, and differentiation and maturation of newborn neurons in adult HD mouse hippocampus have been reported. No significant alteration in adult neurogenesis in the SVZ has been observed in the same mouse models. In contrast, in postmortem samples from HD patients, adult neurogenesis in the SVZ is impaired, and there is greater than normal cell proliferation (Curtis et al., 2003, 2012). Here, we suggest that the depressive behavior observed in patients is not just an epiphenomenon to a fatal disorder, but the result of the modification in the biological function of HTT in the control of mood disorders.

Exogenous expression of the first 1301 aa of HTT with S1181/ S1201 substitutions leads to toxicity in primary culture of striatal neurons by a p53-dependent pathway (Anne et al., 2007). Notably, treatment of striatal neurons in culture with camptothecin, a specific inhibitor of topoisomerase, increases cell death when huntingtin could not be phosphorylated. In contrast, we do not observe a general increase in cell death in the brains of $H d h^{S 1181 A / S 1201 A}$ mice. The most prominent effect of unphosphorylatable HTT in newly generated neurons of the hippocampus is the effect on their survival and maturation. The discrepancies between these studies might be related to the different experimental conditions. In particular, absence of phosphorylation might induce different pathways with distinct outputs according to the cellular context. Future studies are required to establish whether under specific challenges such as DNA damage, the 
$H d h^{S 1181 A / S 1201 A}$ mouse line is more prone to increased cell death or to develop HD related symptoms.

S1181/1201 are Cdk5 phosphorylation sites (Anne et al., 2007). Consistent with our results, a recent report suggests that Cdk5/p35 participates in depression-like behavior in rat through a neurogenesis-dependent mechanism. Cdk5 activity is induced in the hippocampus upon the chronic mild stress (CMS) procedure that leads to a depressive phenotype (Zhu et al., 2012). The authors show that hippocampal Cdk5 activity is required to induce the CMS depressive-related behavior. Moreover, antidepressants decrease Cdk5 activity.

Cdk5 has been implicated in a wide range of cellular mechanisms including those contributing to embryonic and adult neurogenesis (Jessberger et al., 2009; Su and Tsai, 2011). In the adult brain, Cdk5 regulates spine formation. Overactivation of Cdk5 leads to a transient increase in dendritic spine density in the adult hippocampus, followed by a reduction in spine formation (Fischer et al., 2005). Another study showed that inhibition of Cdk5 activity in newly generated neurons of the adult hippocampus interferes with the formation of mature spines (Jessberger et al., 2008). Interestingly, the genetic ablation of Cdk5 from hippocampal neurons specifically impacts on the survival and maturation of neurons, but not on their proliferation (Lagace et al., 2008). What are the molecular mechanisms underlying the effects of Cdk5 in hippocampal neurogenesis and behavior in rodent models? Here we propose that HTT-mediated BDNF axonal transport by Cdk5 may be involved. Indeed, our findings are in agreement with the reported role of Cdk5 in the regulation of anterograde and retrograde axonal transport (Morfini et al., 2004; Shea et al., 2004; Pandey and Smith, 2011). However, the literature does not always fit with the absence of HTT phosphorylation, corresponding to low Cdk5 activity, leading to increased transport and neurogenesis. In our experimental systems (this work and Anne et al., 2007), constitutively S1181/S1201 phosphorylated HTT behaves like the wild-type HTT. Possibly, HTT is constitutively phosphorylated by Cdk5, and it is the dephosphorylation event which is the critical switch leading to the dynamic regulation of induced molecular mechanisms.

BDNF is a neurotrophin involved in mood disorders. BDNF is less abundant in postmortem tissue taken from patients with major depression disorder and in the serum of patients with major depression disorder than controls (Autry and Monteggia, 2012). Most effective treatments of depression stimulate BDNF production; they include electroconvulsive therapy, classical antidepressant drugs, and repetitive transcranial magnetic stimulation. Patients treated with antidepressants long-term show increased levels of BDNF in their serum and hippocampus (Duman and Monteggia, 2006). BDNF is essential for adult neurogenesis in the hippocampus where it specifically increases maturation and survival of the newly generated neurons (Scharfman et al., 2005; Krishnan and Nestler, 2008). It is less clear whether BDNF has a role in cell proliferation. This may be because progenitors are more likely to express TrkB as their morphology become more mature (Donovan et al., 2008). Note that in our Hdh ${ }^{\text {S1181A/S1201A }}$ mouse line, neuronal maturation and survival are greater than in controls but no effect on proliferation was detected. This underlines the specific effect of unphosphorylatable HTT on BDNF.

ProBDNF is processed to mature BDNF by several mechanisms (Lu et al., 2005). The question of whether proBDNF is transient as it is rapidly converted to mature BDNF, or whether it functions as an extracellular ligand is a matter of discussion (Matsumoto et al., 2008; Yang et al., 2009). Both pathways could coexist according to several factors. The site of BDNF production is essential as the enzymes responsible for BDNF maturation have precise subcellular localization. In addition, the conversion could be developmentally regulated with proBDNF actions that may be more robust during postnatal development compared with adulthood. Furthermore, the nature of the BDNF transcript is crucial for its targeting. In our experimental paradigm, we found a specific enrichment in mature BDNF versus proBDNF. We also showed that specific $b d n f$ transcripts are elevated in the presence of S1181/S1201 unphosphorylated huntingtin. One could speculate that these transcripts would be preferentially distributed to cellular compartments where they would be processed rapidly. In addition, extracellular proBDNF might either have a short halflife or act rapidly as a ligand that is endocytosed.

Several classes of drugs with antidepressant activity have been developed. Nevertheless, many patients do not respond to the molecules currently available, and for many others the effects are incomplete (Kupfer et al., 2012). As a consequence, new classes of antidepressant need to be developed and this will inevitably require a sound understanding of the neurobiological basis of this complex disease. The observation that HTT is a determinant of mouse anxiety/depression-related behavior identifies HTT as a component of the pathways regulating mood disorders. Our work thus suggests that it may constitute a novel target for therapy for anxiety and depression not only in HD but also in mood disorders.

\section{References}

Anne SL, Saudou F, Humbert S (2007) Phosphorylation of huntingtin by cyclin-dependent kinase 5 is induced by DNA damage and regulates wildtype and mutant huntingtin toxicity in neurons. J Neurosci 27:73187328. CrossRef Medline

Autry AE, Monteggia LM (2012) Brain-derived neurotrophic factor and neuropsychiatric disorders. Pharmacol Rev 64:238-258. CrossRef Medline

Baquet ZC, Gorski JA, Jones KR (2004) Early striatal dendrite deficits followed by neuron loss with advanced age in the absence of anterograde cortical brain-derived neurotrophic factor. J Neurosci 24:4250-4258. CrossRef Medline

Boldrini M, Hen R, Underwood MD, Rosoklija GB, Dwork AJ, Mann JJ, Arango V (2012) Hippocampal angiogenesis and progenitor cell proliferation are increased with antidepressant use in major depression. Biol Psychiatry 72:562-571. CrossRef Medline

Cattaneo E, Zuccato C, Tartari M (2005) Normal huntingtin function: an alternative approach to Huntington's disease. Nat Rev Neurosci 6:919930. CrossRef Medline

Caviston JP, Ross JL, Antony SM, Tokito M, Holzbaur EL (2007) Huntingtin facilitates dynein/dynactin-mediated vesicle transport. Proc Natl Acad Sci U S A 104:10045-10050. CrossRef Medline

Cohen S, Greenberg ME (2008) Communication between the synapse and the nucleus in neuronal development, plasticity, and disease. Annu Rev Cell Dev Biol 24:183-209. CrossRef Medline

Colin E, Zala D, Liot G, Rangone H, Borrell-Pagès M, Li XJ, Saudou F, Humbert S (2008) Huntingtin phosphorylation acts as a molecular switch for anterograde/retrograde transport in neurons. EMBO J 27:2124-2134. CrossRef Medline

Curtis MA, Penney EB, Pearson AG, van Roon-Mom WM, Butterworth NJ, Dragunow M, Connor B, Faull RL (2003) Increased cell proliferation and neurogenesis in the adult human Huntington's disease brain. Proc Natl Acad Sci U S A 100:9023-9027. CrossRef Medline

Curtis MA, Low VF, Faull RL (2012) Neurogenesis and progenitor cells in the adult human brain: a comparison between hippocampal and subventricular progenitor proliferation. Dev Neurobiol 72:990-1005. CrossRef Medline 
David DJ, Samuels BA, Rainer Q, Wang JW, Marsteller D, Mendez I, Drew M, Craig DA, Guiard BP, Guilloux JP, Artymyshyn RP, Gardier AM, Gerald C, Antonijevic IA, Leonardo ED, Hen R (2009) Neurogenesisdependent and -independent effects of fluoxetine in an animal model of anxiety/depression. Neuron 62:479-493. CrossRef Medline

Donovan MH, Yamaguchi M, Eisch AJ (2008) Dynamic expression of TrkB receptor protein on proliferating and maturing cells in the adult mouse dentate gyrus. Hippocampus 18:435-439. CrossRef Medline

Dragatsis I, Levine MS, Zeitlin S (2000) Inactivation of Hdh in the brain and testis results in progressive neurodegeneration and sterility in mice. Nat Genet 26:300-306. CrossRef Medline

Duff K, Paulsen JS, Beglinger LJ, Langbehn DR, Stout JC (2007) Psychiatric symptoms in Huntington's disease before diagnosis: the predict-HD study. Biol Psychiatry 62:1341-1346. CrossRef Medline

Duman RS, Monteggia LM (2006) A neurotrophic model for stress-related mood disorders. Biol Psychiatry 59:1116-1127. CrossRef Medline

Duyao MP, Auerbach AB, Ryan A, Persichetti F, Barnes GT, McNeil SM, Ge P, Vonsattel JP, Gusella JF, Joyner AL (1995) Inactivation of the mouse Huntington's disease gene homolog Hdh. Science 269:407-410. CrossRef Medline

Engelender S, Sharp AH, Colomer V, Tokito MK, Lanahan A, Worley P, Holzbaur EL, Ross CA (1997) Huntingtin-associated protein 1 (HAP1) interacts with the p150Glued subunit of dynactin. Hum Mol Genet 6:2205-2212. CrossRef Medline

Fischer A, Sananbenesi F, Pang PT, Lu B, Tsai LH (2005) Opposing roles of transient and prolonged expression of p25 in synaptic plasticity and hippocampus-dependent memory. Neuron 48:825-838. CrossRef Medline

Gambazzi L, Gokce O, Seredenina T, Katsyuba E, Runne H, Markram H, Giugliano M, Luthi-Carter R (2010) Diminished activity-dependent brain-derived neurotrophic factor expression underlies cortical neuron microcircuit hypoconnectivity resulting from exposure to mutant huntingtin fragments. J Pharmacol Exp Ther 335:13-22. CrossRef Medline

Gauthier LR, Charrin BC, Borrell-Pagès M, Dompierre JP, Rangone H, Cordelières FP, De Mey J, MacDonald ME, Lessmann V, Humbert S, Saudou F (2004) Huntingtin controls neurotrophic support and survival of neurons by enhancing BDNF vesicular transport along microtubules. Cell 118:127-138. CrossRef Medline

Gil-Mohapel J, Simpson JM, Ghilan M, Christie BR (2011) Neurogenesis in Huntington's disease: can studying adult neurogenesis lead to the development of new therapeutic strategies? Brain Res 1406:84-105. CrossRef Medline

Godin JD, Colombo K, Molina-Calavita M, Keryer G, Zala D, Charrin BC, Dietrich P, Volvert ML, Guillemot F, Dragatsis I, Bellaiche Y, Saudou F, Nguyen L, Humbert S (2010) Huntingtin is required for mitotic spindle orientation and mammalian neurogenesis. Neuron 67:392-406. CrossRef Medline

Jessberger S, Aigner S, Clemenson GD Jr, Toni N, Lie DC, Karalay O, Overall R, Kempermann G, Gage FH (2008) Cdk5 regulates accurate maturation of newborn granule cells in the adult hippocampus. PLoS Biol 6:e272. CrossRef Medline

Jessberger S, Gage FH, Eisch AJ, Lagace DC (2009) Making a neuron: Cdk5 in embryonic and adult neurogenesis. Trends Neurosci 32:575-582. CrossRef Medline

Keryer G, Pineda JR, Liot G, Kim J, Dietrich P, Benstaali C, Smith K, Cordelières FP, Spassky N, Ferrante RJ, Dragatsis I, Saudou F (2011) Ciliogenesis is regulated by a huntingtin-HAP1-PCM1 pathway and is altered in Huntington disease. J Clin Invest 121:4372-4382. CrossRef Medline

Kirkwood SC, Su JL, Conneally P, Foroud T (2001) Progression of symptoms in the early and middle stages of Huntington disease. Arch Neurol 58:273-278. CrossRef Medline

Kobayashi H, Yokoyama M, Matsuoka Y, Omori M, Itano Y, Kaku R, Morita K, Ichikawa H (2008) Expression changes of multiple brain-derived neurotrophic factor transcripts in selective spinal nerve ligation model and complete Freund's adjuvant model. Brain Res 1206:13-19. CrossRef Medline

Krishnan V, Nestler EJ (2008) The molecular neurobiology of depression. Nature 455:894-902. CrossRef Medline

Kupfer DJ, Frank E, Phillips ML (2012) Major depressive disorder: new clinical, neurobiological, and treatment perspectives. Lancet 379: 1045-1055. CrossRef Medline

Lagace DC, Benavides DR, Kansy JW, Mapelli M, Greengard P, Bibb JA, Eisch
AJ (2008) Cdk5 is essential for adult hippocampal neurogenesis. Proc Natl Acad Sci U S A 105:18567-18571. CrossRef Medline

Li SH, Gutekunst CA, Hersch SM, Li XJ (1998) Interaction of huntingtinassociated protein with dynactin P150Glued. J Neurosci 18:1261-1269. Medline

Lu B, Pang PT, Woo NH (2005) The yin and yang of neurotrophin action. Nat Rev Neurosci 6:603-614. CrossRef Medline

Malberg JE, Eisch AJ, Nestler EJ, Duman RS (2000) Chronic antidepressant treatment increases neurogenesis in adult rat hippocampus. J Neurosci 20:9104-9110. Medline

Matsumoto T, Rauskolb S, Polack M, Klose J, Kolbeck R, Korte M, Barde YA (2008) Biosynthesis and processing of endogenous BDNF: CNS neurons store and secrete BDNF, not pro-BDNF. Nat Neurosci 11: 131-133. CrossRef Medline

McGuire JR, Rong J, Li SH, Li XJ (2006) Interaction of huntingtinassociated protein-1 with kinesin light chain: implications in intracellular trafficking in neurons. J Biol Chem 281:3552-3559. CrossRef Medline

Morfini G, Szebenyi G, Brown H, Pant HC, Pigino G, DeBoer S, Beffert U, Brady ST (2004) A novel CDK5-dependent pathway for regulating GSK3 activity and kinesin-driven motility in neurons. EMBO J 23:22352245. CrossRef Medline

Nasir J, Floresco SB, O’Kusky JR, Diewert VM, Richman JM, Zeisler J, Borowski A, Marth JD, Phillips AG, Hayden MR (1995) Targeted disruption of the Huntington's disease gene results in embryonic lethality and behavioral and morphological changes in heterozygotes. Cell 81:811823. CrossRef Medline

Orvoen S, Pla P, Gardier AM, Saudou F, David DJ (2012) Huntington's disease knock-in male mice show specific anxiety-like behaviour and altered neuronal maturation. Neurosci Lett 507:127-132. CrossRef Medline

Pandey JP, Smith DS (2011) A Cdk5-dependent switch regulates Lis1/ Ndel1/dynein-driven organelle transport in adult axons. J Neurosci 31: 17207-17219. CrossRef Medline

Pardo R, Molina-Calavita M, Poizat G, Keryer G, Humbert S, Saudou F (2010) pARIS-htt: an optimised expression platform to study huntingtin reveals functional domains required for vesicular trafficking. Mol Brain 3:17. CrossRef Medline

Perera TD, Dwork AJ, Keegan KA, Thirumangalakudi L, Lipira CM, Joyce N, Lange C, Higley JD, Rosoklija G, Hen R, Sackeim HA, Coplan JD (2011) Necessity of hippocampal neurogenesis for the therapeutic action of antidepressants in adult nonhuman primates. PLoS One 6:e17600. CrossRef Medline

Petrik D, Lagace DC, Eisch AJ (2012) The neurogenesis hypothesis of affective and anxiety disorders: are we mistaking the scaffolding for the building? Neuropharmacology 62:21-34. CrossRef Medline

Rainer Q, Xia L, Guilloux JP, Gabriel C, Mocaer E, Hen R, Enhamre E, Gardier AM, David DJ (2011) Beneficial behavioural and neurogenic effects of agomelatine in a model of depression/anxiety. Int J Neuropsychopharmacol 15:321-335. CrossRef 21473810

Reiner A, Del Mar N, Meade CA, Yang H, Dragatsis I, Zeitlin S, Goldowitz D (2001) Neurons lacking huntingtin differentially colonize brain and survive in chimeric mice. J Neurosci 21:7608-7619. Medline

Sahay A, Scobie KN, Hill AS, O'Carroll CM, Kheirbek MA, Burghardt NS, Fenton AA, Dranovsky A, Hen R (2011) Increasing adult hippocampal neurogenesis is sufficient to improve pattern separation. Nature 472:466470. CrossRef Medline

Samuels BA, Hen R (2011) Neurogenesis and affective disorders. Eur J Neurosci 33:1152-1159. CrossRef Medline

Santarelli L, Saxe M, Gross C, Surget A, Battaglia F, Dulawa S, Weisstaub N, Lee J, Duman R, Arancio O, Belzung C, Hen R (2003) Requirement of hippocampal neurogenesis for the behavioral effects of antidepressants. Science 301:805-809. CrossRef Medline

Scharfman H, Goodman J, Macleod A, Phani S, Antonelli C, Croll S (2005) Increased neurogenesis and the ectopic granule cells after intrahippocampal BDNF infusion in adult rats. Exp Neurol 192:348-356. CrossRef Medline

Shea TB, Yabe JT, Ortiz D, Pimenta A, Loomis P, Goldman RD, Amin N, Pant HC (2004) Cdk5 regulates axonal transport and phosphorylation of neurofilaments in cultured neurons. J Cell Sci 117:933-941. CrossRef Medline

Su SC, Tsai LH (2011) Cyclin-dependent kinases in brain development and disease. Annu Rev Cell Dev Biol 27:465-491. CrossRef Medline 
Surget A, Saxe M, Leman S, Ibarguen-Vargas Y, Chalon S, Griebel G, Hen R, Belzung C (2008) Drug-dependent requirement of hippocampal neurogenesis in a model of depression and of antidepressant reversal. Biol Psychiatry 64:293-301. CrossRef Medline

Taylor AM, Blurton-Jones M, Rhee SW, Cribbs DH, Cotman CW, Jeon NL (2005) A microfluidic culture platform for CNS axonal injury, regeneration and transport. Nat Methods 2:599-605. CrossRef Medline

Wang JW, David DJ, Monckton JE, Battaglia F, Hen R (2008) Chronic fluoxetine stimulates maturation and synaptic plasticity of adult-born hippocampal granule cells. J Neurosci 28:1374-1384. CrossRef Medline

White JK, Auerbach W, Duyao MP, Vonsattel JP, Gusella JF, Joyner AL, MacDonald ME (1997) Huntingtin is required for neurogenesis and is not impaired by the Huntington's disease CAG expansion. Nat Genet 17:404-410. CrossRef Medline

Yang J, Siao CJ, Nagappan G, Marinic T, Jing D, McGrath K, Chen ZY, Mark W, Tessarollo L, Lee FS, Lu B, Hempstead BL (2009) Neuronal release of proBDNF. Nat Neurosci 12:113-115. CrossRef Medline

Zala D, Colin E, Rangone H, Liot G, Humbert S, Saudou F (2008) Phosphorylation of mutant huntingtin at S421 restores anterograde and retrograde transport in neurons. Hum Mol Genet 17:3837-3846. CrossRef Medline

Zala D, Hinckelmann MV, Yu H, Lyra da Cunha MM, Liot G, Cordelières FP,
Marco S, Saudou F (2013) Vesicular glycolysis provides on-board energy for fast axonal transport. Cell 152:479-491. CrossRef Medline

Zeitlin S, Liu JP, Chapman DL, Papaioannou VE, Efstratiadis A (1995) Increased apoptosis and early embryonic lethality in mice nullizygous for the Huntington's disease gene homologue. Nat Genet 11:155-163. CrossRef Medline

Zheng F, Zhou X, Moon C, Wang H (2012) Regulation of brain-derived neurotrophic factor expression in neurons. Int J Physiol Pathophysiol Pharmacol 4:188-200. Medline

Zhu WL, Shi HS, Wang SJ, Xu CM, Jiang WG, Wang X, Wu P, Li QQ, Ding ZB, Lu L (2012) Increased Cdk5/p35 activity in the dentate gyrus mediates depressive-like behaviour in rats. Int J Neuropsychopharmacol 15: 795-809. CrossRef Medline

Zuccato C, Tartari M, Crotti A, Goffredo D, Valenza M, Conti L, Cataudella T, Leavitt BR, Hayden MR, Timmusk T, Rigamonti D, Cattaneo E (2003) Huntingtin interacts with REST/NRSF to modulate the transcription of NRSE-controlled neuronal genes. Nat Genet 35:76-83. CrossRef Medline

Zuccato C, Valenza M, Cattaneo E (2010) Molecular mechanisms and potential therapeutical targets in Huntington's disease. Physiol Rev 90:905-981. CrossRef Medline 